\title{
Commentary: Multicellular Features of Phytoplankton
}

\author{
Karen van Niekerk* and Andrew Ndhlovu \\ Evolution of Complexity Laboratory, Evolutionary Studies Institute, University of the Witwatersrand, Johannesburg, South \\ Africa
}

Keywords: multicellularity, multilevel selection theory, phytoplankton, programmed cell death, evolutionary transitions in individuality

\section{A Commentary on}

Multicellular Features of Phytoplankton

Abada, A., and Segev, E. (2018). Front. Mar. Sci. 5:144. doi: 10.3389/fmars.2018.00144

\section{INTRODUCTION}

Adopting Lyons and Kolter's minimum requirements for multicellularity (Lyons and Kolter, 2015), Abada and Segev provide strong evidence that two major groups of phytoplankton exhibit some of the features associated with multicellular organisms. These minimum requirements are cell-cell adhesion and intercellular communication resulting in coordinated activity. The authors propose

OPEN ACCESS

Edited by:

Hongyue Dang,

Xiamen University, China

Reviewed by:

Giovanna Romano,

Stazione Zoologica Anton Dohrn, Italy Matthew David Herron, Georgia Institute of Technology, United States

*Correspondence:

Karen van Niekerk karenkvn@gmail.com

Specialty section:

This article was submitted to Aquatic Microbiology,

a section of the journal

Frontiers in Marine Science

Received: 06 November 2018 Accepted: 04 February 2019 Published: 26 February 2019

Citation:

van Niekerk K and Ndhlovu A (2019) Commentary: Multicellular Features of Phytoplankton. Front. Mar. Sci. 6:59. doi: 10.3389/fmars.2019.00059 that phytoplankton may represent "an intermediate state between single cells and aggregates of physically attached cells that communicate and cooperate." We find their account of multicellular features and multicellular examination of programmed cell death (PCD) in phytoplankton to be a useful approach for understanding PCD in these organisms. However, studying the role of PCD in this "intermediate" state would benefit from a more structured framework such as the multilevel selection theory approach to understand both the evolution of multicellularity and the selection and maintenance of PCD in microbial communities.

\section{COOPERATION AND FEATURES OF MULTICELLULARITY IN PHYTOPLANKTON}

The evolution of multicellularity is the premier example of an evolutionary transition in individuality, where individuals of one kind form groups that eventually become new kinds of individuals (Buss, 1987; Michod, 1999). The formation of a cooperative group of single cells, especially under stress conditions, is an essential first step toward multicellularity (Michod, 1997; West et al., 2015). Stress is particularly relevant for phytoplankton, which are frequently exposed to physical and chemical changes in the environment or infected by viruses and bacteria (Bidle, 2016). Abada and Segev cite studies showing that phytoplankton communities respond to stress by releasing stress signaling molecules, resulting in coordinated activities. They also discuss the role of the Transparent Exopolymer Particles produced by phytoplankton in the formation of the buoyant gelatinous layer in the sea surface microlayer, referred to metaphorically as the "sea skin." They propose that the sea skin plays a crucial role in facilitating cell aggregation and preventing sinking. The conditions support the evolution of some of the features of multicellularity. Furthermore, the proposed role for the sea skin in mediating multicellular assemblages highlights the role of public goods and cooperation in the transition to multicellularity, which has been addressed elsewhere (Michod and Roze, 2001). Aggregation and communication are cooperative traits that 
may have evolved to cope with environmental stress, supporting Abada and Segev's suggestion that cooperative units of phytoplankton represent an "evolutionary snapshot toward multicellularity."

\section{THE MULTICELLULAR CONTEXT FOR INTERPRETING PCD}

The authors' view that "phytoplankton populations have multicellular features that encourage examination of PCD in phytoplankton similarly to PCD in metazoans" is thoughtprovoking. While PCD in multicellular organisms may be explained by kin selection, microbial communities consist of genetically unrelated individuals from many taxa, and so there are many other interpretations and evolutionary trajectories for PCD (Durand and Ramsey, 2018). PCD is an important, perhaps even essential, component in the evolution of multicellularity (Iranzo et al., 2014) but in microbial communities many other process are at work (e.g., niche construction, holobiont evolution, group selection, nonadaptive evolution due to genetic drift, etc.). Empirical evidence shows that PCD in phytoplankton may be triggered by a range of abiotic stress conditions including nitrogen and $\mathrm{CO}_{2}$ limitation, UV light, heat and onset of darkness (Bidle, 2016). Biotic factors such as viral infection have also been found to trigger and in some cases recruit the PCD machinery (Bidle et al., 2007). Furthermore, in aquatic environments where microorganisms exist in complex communities with phytoplankton cells, colonies and aggregates (Dang and Lovell, 2016), interactions between bacteria and phytoplankton may play a role in phytoplankton PCD (Bidle, 2016). A more structured and formal analysis of PCD in microbial communities with multilevel selection theory would complement Abada and Segev's multicellularity context to evaluate the evolution of PCD.

\section{MULTILEVEL SELECTION THEORY, PCD AND PHYTOPLANKTON COMMUNITIES}

Multilevel selection theory (MLS) explains how selection can occur at more than one level of the biological hierarchy at the same time (Okasha, 2006). Thus, altruistic traits such as PCD that are disadvantageous at a lower level could be selected for, if they enable groups of cells to outcompete other groups. In an evolutionary transition in individuality, MLS could be used to explain how the interaction between selection at different levels leads to lower-level units ("particles") sacrificing their individuality to become higher-level individuals ("collectives")

\section{REFERENCES}

Bidle, K. D. (2016). Programmed cell death in unicellular phytoplankton. Curr. Biol. 26, R594-R607. doi: 10.1016/j.cub.2016. 05.056

Bidle, K. D., Haramaty, L., Barcelos e Ramos, J., and Falkowski, P. (2007). Viral activation and recruitment of metacaspases in the unicellular
(Okasha, 2006). Using MLS type 1 (MLS1) where the particles (individual phytoplankton cells) are the focal unit, and the fitness of the collective is defined as the average fitness of the particles (Okasha, 2006), an analysis of the multicellular like behavior would formalize the selection of "an intermediate state between single cells and aggregates of physically attached cells that communicate and cooperate." Durand and Ramsey provide an MLS1 mathematical examination of PCD using Price's equation (Durand and Ramsey, 2018), demonstrating that under certain assumptions PCD and fitness have positive covariance, thereby demonstrating that selection for the PCD character occurs at the group level. We believe that this is better examination than the multicellular context offered by Abada and Segev. Furthermore, such an examination may also reveal whether non-adaptive factors play a role, as suggested by Nedelcu et al. (2011).

\section{CONCLUSION}

Abada and Segev propose that phytoplankton "display the characteristics of a multicellular-like community rather than a random collection of individuals." They argue that employing a multicellular context will lead to an understanding of paradoxical characteristics of phytoplankton such as PCD. We think this is helpful, but that a more formal analysis is required to explain the selection and evolution of PCD in the unicellular world. There are many more angles to this apparently paradoxical phenomenon in microbial communities. An MLS1 framework would be useful to assess the multicellular-like traits in phytoplankton proposed by Abada and Segev.

\section{AUTHOR CONTRIBUTIONS}

All authors listed have made a substantial, direct and intellectual contribution to the work, and approved it for publication.

\section{FUNDING}

AN is supported by the Durand Foundation Scholarship for Evolutionary Biology and Phycology (No. DFEBP00001/15). The support of the DST-NRF Centre of Excellence in Palaeosciences (CoE-Pal) toward this research is hereby acknowledged. Opinions expressed and conclusions arrived at are those of the author and are not necessarily to be attributed to the CoE.

\section{ACKNOWLEDGMENTS}

We would like to thank Dr. P. M. Durand for discussions that helped us to frame this commentary.

coccolithophore, Emiliania huxleyi. Proc. Natl. Acad. Sci. U.S.A. 104, 6049-6054. doi: 10.1073/pnas.0701240104

Buss, L. W. (1987). The Evolution of Individuality. Princeton, NJ: Princeton University Press.

Dang, H., and Lovell, C. R. (2016). Microbial surface colonization and biofilm development in marine environments. Microbiol. Mol. Biol. Rev. 80, 91-138. doi: 10.1128/MMBR.00037-15 
Durand, P. M., and Ramsey, G. (2018). The nature of programmed cell death. Biol Theory. 1-12. doi: 10.1007/s13752-018-0311-0

Iranzo, J., Lobkovsky, A. E., Wolf, Y. I., and Koonin, E. V. (2014). Virus-host arms race at the joint origin of multicellularity and programmed cell death. Cell Cycle 13, 3083-3088. doi: 10.4161/15384101.2014.949496

Lyons, N. A., and Kolter, R. (2015). On the evolution of bacterial multicellularity. Curr. Opin. Microbiol. 24, 21-28. doi: 10.1016/j.mib.2014.12.007

Michod, R. E. (1997). Cooperation and conflict in the evolution of individuality. I. multilevel selection of the organism. Am. Nat. 149, 607-645.

Michod, R. E. (1999). Darwinian Dynamics: Evolutionary Transitions in Fitness and Individuality. Princeton, NJ: Princeton University Press.

Michod, R. E., and Roze, D. (2001). Cooperation and conflict in the evolution of multicellularity. Heredity 86, 1-7. doi: 10.1046/j.1365-2540. 2001.00808.x

Nedelcu, A. M., Driscoll, W. W., Durand, P. M., Herron, M. D., and Rashidi, A. (2011). On the paradigm of altruistic suicide in the unicellular world. Evolution 65, 3-20. doi: 10.1111/j.1558-5646.2010.01103.x
Okasha, S. (2006). Evolution and the Levels of Selection. Oxford, UK: Oxford University Press.

West, S. A., Fisher, R. M., Gardner, A., Kiers, E. T., and Mccutcheon, J. P. (2015). Major evolutionary transitions in individuality. Proc. Natl. Acad. Sci. U.S.A. 112, 10112-10119. doi: 10.1073/pnas.1421402112

Conflict of Interest Statement: The authors declare that the research was conducted in the absence of any commercial or financial relationships that could be construed as a potential conflict of interest.

Copyright (C) 2019 van Niekerk and Ndhlovu. This is an open-access article distributed under the terms of the Creative Commons Attribution License (CC BY). The use, distribution or reproduction in other forums is permitted, provided the original author(s) and the copyright owner(s) are credited and that the original publication in this journal is cited, in accordance with accepted academic practice. No use, distribution or reproduction is permitted which does not comply with these terms. 